\title{
Static Model of Labour Force Participation: Survey of Married Women in Zimbabwe
}

Tafadzwa R Chikwanha

Department of Economics, University of Fort Hare, Email: chikwanhat@gmail.com

Free Ncube

Department of Economics, University of Fort Hare, Email: 201013417@ufh.ac.za

\author{
Doi:10.5901/mjss.2014.v5n23p406
}

\begin{abstract}
The study sought to ascertain and measure the determinants of labour force participation of married women in Zimbabwe. The focus was on the activeness of married women in paid, permanent work. The study utilized and collected data from a sample of 514 married women from varying socio-economic backgrounds. A binomial logit model was implemented as the regression model to test the probability of labour market participation by the target group. The results showed that age, education attainment, work experience, geographical location, religious denomination and the amount of non-labour income earned were significant determinants of the decision to work by married women. It was noted conclusively that none of the factors above influenced LFP strongly enough to warrant the low levels of formally and permanently employed married women. It was suggested that economy-wide policies to improve general employment levels be implemented.
\end{abstract}

Keywords: Labour Force Participation, Female Labour Force Participation, Unemployment, Formal sector employment.

\section{Introduction}

Employment in Zimbabwe has since the turn of the century been a complex and controversial issue. Employment or the vast unavailability of it thereof had for years after 2000 been exacerbated amidst questionable and inconsistent economic, social and political policies. The very structures of the Zimbabwean labour market and the economy have combined to form a perpetually decreasing scenario of paid formal permanent employment. Paid formal employment in the study refers to employees and own-account workers employed in formal enterprises and entitled to all of: contribution to pension, paid annual leave, paid sick leave and written contracts by the employer (Zimstat, 2011). Zimbabwe, in what has been termed "The new economy" has over the 2000 to 2014 period experienced a rapid decline in formal sector industry and a surge in indigenous, informal sector businesses (Zimbabwe National Budget, 2014). While this seems logical and favorable given the Government's radical economic empowerment and indigenization drives, it has resulted in an emergence of multitudes of unregistered micro and small enterprises that lack: the diversity, financial capacity to pay taxes, and employment capabilities needed to cater for the country's perennially escalating labour force. Over US\$7.4 billion is said to be circulating within the unregistered, informal sector with Government and tax authorities finding no way of harnessing it into the cash-strapped formal sector (Association for the development of Education ADEA, 2014). This sector is the largest employer in the country and yet it contributes marginally to pension remittances and income taxes.

As a consequence of the prevailing economic conditions, activity in paid, formal employment is largely depressed. Labour market statistics and indicators in Zimbabwe are largely focused on "The new economy." Of the 7 million 15 years + age group population, $87 \%$ are economically active. Of these, a broad unemployment rate of $10.7 \%$ exists (Zimstat, $2012)^{1} .54 \%$ of employment is said to be generated in communal and resettlement work while $35.3 \%$ is classified as other employment. The Labour force survey 2011 conducted by Zimstat (2012) shows that FLFP among rural women is higher than that of their urban counterparts at $90 \%$ and $76.1 \%$ respectively. Naturally, this would be expected in Zimbabwe since rural women tend to be burdened with family welfare and productivity from a younger age compared to urban women who tend to prolong schooling. 50\% of women above 12 years of age in Zimbabwe were married and had a

\footnotetext{
1 These figures generated from the 2011 Labour Force Survey by Zimstat have been very controversial. Questions have been raised as to either their authenticity or the definition (and therefore delimitation of employment) in Zimbabwe. 
Literacy rate of 97\%, a figure amongst the highest in the world. Married women comprise a figure of 2079568 against a total population of just under 12 million (Zimstat, 2012).

Given such figures, it is prudent to classify married women as a separate socio-economic group that has experiences unique to it. The conduct of female supply of labour has essential implications on various socioeconomic phenomena such as fertility, population, marriage, divorce rates, household earnings, gender equity, women emancipation and male-female wage differentials, moreso in low-income economies where male-female disparities are well documented (Killingsworth and Heckman, 1986). In the Zimbabwean scenario, women are gradually moving away from their traditional roles as housewives, child bearers and home-makers. Subject to the various socio-economic phenomena that influence the welfare of married women, it would seem at least logical to understand their labour market practices. As of the same period, only $14.1 \%$ were employed in formal paid work ( $7.9 \%$ permanent work and 6.2 casual work).

While the Zimbabwean economy lacks the general capacity to provide paid, permanent work for the bulk of married women in the country (this is possibly the most significant determinant of getting work), there are various other socioeconomic factors that influence performance in the labour market. This phenomenon is largely disconcerting because the country is lagging on achieving the Millennium Development Goals (MDG). Although various steps have been undertaken to improve the welfare and status of women in the country and their participation in the economy, the major strides have been in informal and communal activities. In terms of providing paid, permanent work, MDG 3, is far from being achieved.

\section{Brief Overview of FLFP in Zimbabwe}

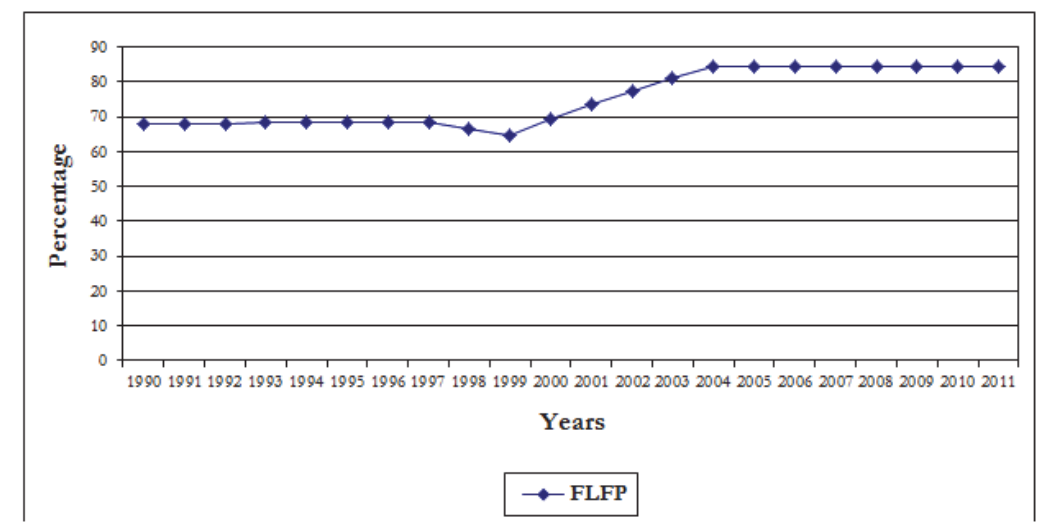

Source: Zimstat (2012), IndexMundi (2013)

Female labour force participation in Zimbabwe has consistently over extended periods of times been surpassed by that of males. A positive growth trend in the country has been observed from 1990 to date. In 1990, total labour force participation stood at $73.8 \%$ with a gender-based disparity of $11.9 \%$. FLFP and MLFP were recorded at $67.9 \%$ and $79.8 \%$ respectively. These statistics show evidence of a historical imbalance in work participation between men and women in Zimbabwe. Improvements in FLFP continued till 1998 and 1999 showed $-2.6 \%$ and $-2.7 \%$ year-on-year changes to 66.4 $\%$ and $64.6 \%$ respectively. The succeeding year recorded a turnaround in participation of women in the labour force. A 7.1\% growth from the 1999 rate to $69.2 \%$ was experienced. Between 2000 and 2011 FLFP improved a remarkable 21.9\% to a high of $84.4 \%$. Recent trends have shown a narrowing gap in the disparity between FLFP and MLFP. By 2011, the gender performance gap had narrowed from the 1990 rate to just $6 \%$ as MLFP was recorded at $90.4 \%$. This has been a consequence of more pronounced gender equity legislation, emancipation of women, societal modernization but largely because of the strenuous economic status quo (combined incomes lead to better livelihoods). Regardless, in terms of formal paid employment, only 14\% of women were active (Zimstat, 2012). The data clearly reveals that women comprised the larger portion of the unemployed population. According to the 2004 Labour force survey by Central Statistical Office CSO (2004)2, LFP of married women above 12 years of age in 2004 was $48.51 \%$ while those for women who were never married and those divorced or widowed were $40.12 \%$ and $11.37 \%$ respectively.

2 The formerly Central Statistical Office (CSO) is now the Zimbabwe National Statistical Agency (Zimstat).

Data collection and National surveys have been known to be inconsistent, largely unreliable and lacking quality. As a consequence, the relevant and more recent data is largely in accessible. Given the prevailing economic status, it is not far-fetched to assume that there have not been significant positive changes in employment of women. 


\section{Literature Review}

\subsection{Theoretical Framework}

In the static labour supply model (absence of inter-temporal optimization), individuals seek to maximize utility from consumption (c) and leisure (I) at a given time (t), subject to a budgetary constraint

$$
c_{i},+l_{i} w_{i}=y_{i}+w_{i} T \text { (1) }
$$

Individuals assume a certain level of optimal utility by selecting between variable magnitudes of consumption and leisure subject to budgetary constraints. The marginal conditions in (2) are achieved where $v$ denotes the marginal utility of money and the individual wage rate equates the marginal rate of substitution, assuming the individual is a labour market participant who consumes $<T$ hours of $I$. Assuming the individual is a non-labour market participant who can consume $T$ leisure hours, condition (3) holds (Myck and Reed, 2005).

$$
\begin{aligned}
& \frac{\partial U_{i}}{\partial c_{i}}=\vartheta_{i}, \frac{\partial U_{i}}{\partial l_{i}}=\vartheta w_{i} \\
& \frac{\partial U_{i}}{\partial c_{i}}=v_{i}, \frac{\partial U_{i}}{\partial l_{i}} \geq \vartheta w_{i}
\end{aligned}
$$

To decipher the labour participation dynamics of couples, the model takes cognizance of the utility maximization options of the individuals subject to their individual and joint consumption and leisure preferences.

$$
U_{i}\left(c_{m}, c_{f}, l_{m}, l_{f}, Q\right)
$$

Unlike the typical Neoclassical labour supply framework which is based on individuality and individual rationality, the 'Couples Model' predicts the maximization of individual utility functions (permitting substitution and complementariness in consumption and leisure) subject to the joint budget constraint. $Q$ denotes the joint consumption on 'public' goods. The model shows that the consumption of 'private' goods by an individual in the couple directly enters the utility function of the other.

$$
c+l_{m} w_{m}+l_{f} w_{f}=y_{m}+y_{f}+y_{o}+w_{m} T+w_{f} T
$$

Where $c, w_{m f}, y_{m f}$ denote total consumption, wages and individual non-labour income respectively. $y_{0}$ is non-labour income which cannot be assigned individually. Given $\theta$ as representative of the woman's welfare weight, (1- $\theta)$ obviously represents the welfare of the man. Through application of the second theorem of the economics of welfare, Pareto Optimality will be achieved as answer to the maximization equation (6).

$$
\operatorname{Max} \theta * U_{f}\left(c_{f}, c_{m}, l_{f}, l_{m}, Q\right)+(1-\theta) * U_{m}\left(c_{f}, c_{m}, l_{f}, l_{m}, Q\right)
$$

Assuming estimation of a log-linear specification:-

$$
H_{i}=\alpha \ln w_{i}+\beta X_{i}+u_{i}
$$

With:-

$\beta X_{i}=\lambda V_{i}+\varphi Y_{i}$

$V_{i}$ is a vector of factors that determine the extent of one's work, these include age, residence, experience, religion etc and $Y_{i}$ is value/measure of total unearned income.

\subsection{Review of Empirical Literature}

The improvement in the education of women and their involvement in varying socioeconomic structures have prompted research on their labour market activities. Many studies on the participation of women in the labour force have been conducted in relatively more economically developed countries. Empirical literature is less available low income economies.

Jaumotte (2003) tested the determinants of FLFP in seventeen OECD countries. The study focused on the 1985 to 1999 period and employed Multivariate regression analyses. Variables such as policy instruments on tax equity, child care subsidies, child care benefits, paid maternity and parental leaves were included. The study also disaggregated between full time and part-time employees. The results showed a positive effect of more neutral taxes on FLFP. Child care benefits showed statistically significant negative impact on FLFP. Their lump sum nature triggered a strong enough income effect that discouraged work.

In a related South African study, Ntuli (2007) sought to determine the causes of the significant rise in labour force participation of women from 1995 to 2004. The study implemented a decomposition technique to study data over the 10 
year period. The findings showed LFP of women, which was consistently lower than that of men, was significantly positively influenced by education attainments. Other factors such as the amount of non-labour income, marriage, fertility and geographical locations had impacts on the participation of women in the labour market.

Yakubu (2010) conducted a study to ascertain factors influencing FLFP in South Africa in 2008. Using the Human Capital Theory as the underlying theory, the study employed secondary data from Statistics South Africa (StatsSA) Quarterly Labour Force Survey and estimated a logistic regression. The study established that strong influences of education existed. Exponential growths in the odds of being employed were observed as one was more educated. When marriage was included in the model, the odds generally fell for all education levels.

Floro and Kimatsu (2011) analysed the South African Time Use Survey of 2000 to identify and understand labour market and subsistence work practices that were missed by the Labour Force Survey. The study also assessed time spent during job search and household work to determine the extent of gender inequality in the labour market and the household. 10465 men and women of working age were studied and it was concluded that no significant variances existed between labour market patterns of men and women.

Klasen and Pieters (2012) studied the Push and Pull driver of FLFP during India's economic boom. The study focused on urban LFP between 1987 and 2004. The study showed that lowly educated women were driven into the labour force by necessity rather than positive incentives to work. Conversely, highly educated women were driven to work by positive pull factors such as attractive remuneration and working conditions. FLFP improved more for lowly educated women compared to their learned counterparts.

Knobloch (2013) in an American-based study sought to determine the influences of the varying child care costs in the different States on FLFP. The study utilized the Ordinary Least Squares estimation technique to test the model. The results showed that child care costs were a statistically significant determinant of FLFP. The child care costs influenced FLFP positively contrary to the study a priori stipulation.

\section{Methodology}

The dependent variable $L F P_{i}$ is a censored one in which some of the variables may take a zero value representative of non-participants. This will obviously result in biased coefficients. Given that for some respondents LFP=0, then it would be prudent to utilize a binary response model as shown in the succeeding section.

\subsection{Empirical Model}

The econometric model adopts key explanatory variables from the theoretical framework. The complementary of the slope parameters are adopted from literature.

$L F P=f\left(\begin{array}{l}A G E, E D U C, D E P B 10, \text { LMEXP, RESIDENCE, DENOMINATION, HUSEDUC, } \\ \text { HUSAGE, HUSWORKHRS, HUSINC, HHINC, MOTHEREDUC, FATHEREDUC }\end{array}\right)$

Where:- AGE: respondent's age

EDUC: education level (years)

DEPB10: number of dependents below 10 years of age

LMEXP: labour market experience

RESIDENCE: location of respondent's residence

DENOMINATION: respondent's denomination

HUSEDUC: husband's education (years)

HUSAGE: husband's age

HUSWORKHRS: husband's working hours

HUSINC: husband's income

HHINC: household income

MOTHEREDUC: mother's education

FATHEREDUC: father's education

To estimate the impacts of the slope parameters on the dependent binary variable, the study uses a logit regression model.

$$
\{\operatorname{Pr}(L F P=1 \mid x)\}=\log \left[\frac{\operatorname{Pr}(L P F=1 \mid x)}{1-\operatorname{Pr}(L F P=1 \mid x)}\right]=\alpha_{0}+x^{\prime} \delta
$$

Where $\mathrm{a}_{0}$ is the constant term and $\delta$ is the vector of slope parameters (Hosmer and Lemeshow, 1989 cited in So, 1995) 


\section{Empirical Findings}

Table 1: Chi-Square Correlations to LFP

\begin{tabular}{|c|c|c|c|c|c|c|c|c|c|c|c|c|c|c|}
\hline & LFP & C1 & C2 & C3 & C4 & C5 & C6 & C7 & C8 & C9 & C10 & C11 & C12 & C13 \\
\hline LFP & 1 & -.05 & $.20^{* *}$ & -.02 & $.37^{* *}$ & $.22^{* *}$ & $-.23^{* *}$ & .07 & -.06 & -.07 & -.04 & $.13^{* *}$ & .07 & .03 \\
\hline & & .211 & .000 & .675 & .000 & .000 & .000 & .138 & .205 & .092 & .333 & .002 & .119 & .450 \\
\hline & 514 & 514 & 514 & 514 & 514 & 514 & 514 & 514 & 514 & 514 & 514 & 514 & 514 & 514 \\
\hline
\end{tabular}

The Chi-square correlation tests were conducted to test the degree of linear association between the variables. The test is a measure of symmetry between the dependent and the chosen explanatory variable and in no way implies causality between the LHS and RHS of the model. The test is a primary test that merely provides evidence that movements in variables are at least related subject to a correlation coefficient (Brooks, 2008). Two-tailed tests at $5 \%$ and $1 \%$ significant levels were utilized. The tests are reduced to provide for stricter rejection criterion such that the null hypothesis is rejected less often. This has the advantage of reducing the Type I error but has the disadvantage of increasing probability of Type II error. The correlation tests showed that education, labour market experience, residence, denomination and husband's income are significantly correlated to labour force participation of the married woman at $1 \%$ s.l. The work experience, residence and denomination variables show relatively stronger correlation with the dependent variable compared to the others.

Table 2: Regression findings

\begin{tabular}{|l|c|c|c|c|c|c|}
\hline & B & S.E. & Wald & df & Sig. & $\operatorname{Exp(B)}$ \\
\hline Age & -.133 & .032 & 16.865 & 1 & .000 & .876 \\
\hline Educ & .208 & .070 & 8.851 & 1 & .003 & 1.232 \\
\hline Depb10 & -.030 & .095 & .098 & 1 & .754 & .971 \\
\hline Lmexp & .135 & .019 & 52.231 & 1 & .000 & 1.144 \\
\hline Residence & .903 & .279 & 10.492 & 1 & .001 & 2.468 \\
\hline Denomination & -1.423 & .263 & 29.335 & 1 & .000 & .241 \\
\hline Huseduc & -.022 & .051 & .183 & 1 & .668 & .978 \\
\hline Husage & .002 & .030 & .003 & 1 & .960 & 1.002 \\
\hline Husworkhrs & -.001 & .000 & 19.604 & 1 & .000 & .999 \\
\hline Husinc & -.309 & .059 & 27.207 & 1 & .000 & .734 \\
\hline Hhinc & .000 & .000 & 31.199 & 1 & .000 & 1.000 \\
\hline Mothereduc & -.037 & .043 & .741 & 1 & .389 & .964 \\
\hline Fathereduc & -.021 & .041 & .257 & 1 & .612 & .979 \\
\hline Constant & 4.767 & 1.347 & 12.516 & 1 & .000 & 117.554 \\
\hline
\end{tabular}

a. Variable(s) entered on step 1: AGE, EDUC, DEPB10, LMEXP, RESIDENCE, DENOMINATION, HUSEDUC, HUSAGE, HUSWORKHRS, HUSINC, HHINC, MOTHEREDUC, FATHEREDUC.

Table 2 illustrates the findings of the logistic regression analysis. 13 explanatory variables were included in the model with a large number of them expected to be statistically significant regressors as postulated by the theoretical underpinning. The primary results of the regression analysis are expressed as the log odds or the logarithm of the odds of the event occurring versus its non-occurrence. Although the former is not commonly utilized in the inference of results because of interpretational complexities, it is vital in determining the direction of influence of the variable on the regressand. Excluding the constant term, 8 of the explanatory variable were statistically significant $(p / s i g<$ or $=0.05)$ and Wald statistic greater than or equal to 2 (Wald $>$ or $=2$ ). These findings show that the model was well specified.

As indicated by $\operatorname{Exp}(B) / o d d s$ ratio, the age variable shows that younger married women were 0.876 times more likely to be formally employed than their older counterparts. The education variable shows that the odds of highly educated married women being formally employed were 1.23 times more than those of less educated women. To add on, respondents with more work experience were 1.14 times more likely to be formally employed compared to those with less or no labour market experience.

The residence variable which captures the impact of geographical location of residence of respondents on their 
chances of being formally employed shows that the respondents in urban areas were nearly 2.5 times more likely to work formally relative to their non-urban residing peers. The denomination variable was included to capture the impact of religious principles on married women's working patterns. Zimbabwe is infamous for certain religious sects which inhibit women from working. The findings show that women in non-orthodox (i.e. Apostolic Faith sects) were 0.24 times likely to be either in informal employment or unemployed relative to those in orthodox denominations.

The variables included to capture the 'Couples' impact where largely significant. The odds of being formally employed of women whose husbands' work hours exceeded 40 hours/week were 0.999 times less than those whose partners worked less than 40 hours/week. Women whose husbands' incomes and total household income is very high were 0.734 and 1 time(s) less and more likely to be formally employed respectively.

\section{Conclusions}

While it is clear and indisputable that the state of the Zimbabwe economy is the strongest determinant of the acquisition of formal employment in the country, the study revealed other household and individual-based variables that affect the possibility of work among women. It can be concluded from the findings that age, education attainment, work experience, geographical location, religious denomination and the amount of non-labour income earned are significant determinants of the decision to work by married women. Contrary to expectations, fertility (stage and level) proved to be an insignificant determinant of the decision framework.

It is logical to conclude that the factors influencing the LFP of married women are intrinsic to their households and persona. These factors though, do not account for the shockingly low levels of formal sector employment of married women. Policy frameworks aimed at improving the status of women in the labour market has little it can achieve by targeting or focusing on latter and their specific labour market needs. It is recommended that in order to achieve the employment targets of women, reduce labour market differentials across gender lines and to achieve steps towards MDG 3 , there is need to improve the general performance of the economy. General improvements in investment, business performance and economic growth would unquestionably improve the welfare of women in Zimbabwe. Rather than directing effort towards short run benefits that accrue to women, there is need for overall economic revamp to attain long term benefits and employment for all.

\section{References}

Association for the Development of Education in Africa ADEA (2014) "Livelihood opportunities for youth in the informal sector." [Online]. Accessed: 17 July 2014. Available: http://www.adeanet.org/portalv2/sites

Aysit, T. (2002) "Economic Development and Female Labour Force Participation in Turkey: Time Series evidence and cross-province estimates. Economic Research Centre. 01(05).

Brooks, C., (2008) "Introductory Econometrics for Finance."Cambridge University Press.

Central Statistical Office (2004) "2004 Labour Force Survey." Zimbabwe National Statistical Agency.

Chevalier, A. and Vittanen, T.K. (2002) "The causality between female labour force participation and the availability of childcare." Applied Economics Letters.

Eyal, K. and Woolard, I. (2011) "Female Labour Force Participation and South Africa's Child Support Grant." Southern African Labour and Development Research Unit.

Floro, M.S. and Komatsu, H. (2011) "Labour Force Participation, Gender and Work in South Africa: What can Time Use data reveal." Feminist Economics.

Gujarati, D.N., (2004) "Basic Econometrics." McGraw-Hill International.

Jaumotte, F. (2003), "Female Labour Force Participation: Past Trends and Main Determinants in OECD Countries"OECD Economics Department Working Papers, No. 376, OECD Publishing.

Killingsworth, M.K. and Heckman, J.J. (1986) "Handbook of Labour Economics." Elsevier Science Publishers.

Klasen, S. and Pieters, J. (2012) "Push or Pull? Drivers of Female Labour Force Participation during India's Economic boom." Institute of the study of labour.

Knobloch, K. (2003) "Differences in Child Care Costs between States and their influence on FLFP." Major themes in Economics.

Mincer, J. (1962) "Labour Force Participation of Married Women: A study of Labour Supply. National Bureau of Economic Research.

Myck, M., and Reed, H., (2005) "A Review of Static and Dynamic Models of Labour Supply and Labour Market Transitions." The Institute of Fiscal Studies. 06(15) 10-31.

Ntuli, M. (2007) "Determinants of South African Women's Labour Force Participation, 1995-2004." Institute of Labour Studies.

So, Y., (1995) "A Tutorial on Logistic Regression." SAS Institute Inc. North Carolina.

Yakubu, A.Y. (2010) "Factors influencing Female labour force participation in South Africa in 2008." The African Statistical Journal.

Zimbabwe National Budget (2014). "2014 National Budget." As presented by Finance Minister Chinamasa.

Zimstat (2012) "2011 Labour Force Survey." Zimbabwe National Statistical Agency. 